\title{
Fast Determination of Phenolic Compounds in Brazilian Wines from Vale do São Francisco Region by CE
}

\author{
Fábio de Souza Dias • Aline Klassen • \\ Marina Franco Maggi Tavares · Jorge Maurício David
}

Received: 27 October 2012/Revised: 3 January 2013/Accepted: 14 January 2013/Published online: 12 February 2013

(C) Springer-Verlag Berlin Heidelberg 2013

\begin{abstract}
Six phenolic compounds were separated and determined by capillary zone electrophoresis in red wine from Brazil's region Vale do São Francisco with total analysis time of $12 \mathrm{~min}$. The limit of detections varied from 1.59 to $2.24 \mathrm{mg} \mathrm{L}^{-1}$. The relative standard deviations (for $n=6$ ) varied from 0.28 to $3.50 \%$. The red wine samples analyzed were bought in the local market and the phenolic compound recoveries were in the range of 98-101\%. The concentrations of gallic acid in the samples of wines varied from 16.0 to $42.0 \mathrm{mg} \mathrm{L}^{-1}$, caffeic acid (3.16-5.18 $\left.\mathrm{mg} \mathrm{L}^{-1}\right)$, syringic acid $\left(5.73-13.0 \mathrm{mg} \mathrm{L}^{-1}\right)$, kaempferol $\left(2.32-4.33 \mathrm{mg} \mathrm{L}^{-1}\right)$, quercetin (1.68-4.03 $\left.\mathrm{mg} \mathrm{L}^{-1}\right)$, myricetin $\left(7.52-25.1 \mathrm{mg} \mathrm{L}^{-1}\right)$. The concentrations found agree with data reported in the literature.
\end{abstract}

Keywords CZE · Phenolic compounds · Wines

\section{Introduction}

Phenolic compounds constitute one of the most important quality parameters of wine, because those compounds have a great impact on the sensorial characteristics, especially

F. de S. Dias $(\square)$

Centro de Ciências Exatas e Tecnológicas, Universidade Federal do Recôncavo da Bahia, Campus Universitário de Cruz das Almas, Cruas das Almas, Bahia 44380-000, Brazil e-mail: fsdias@ufrb.edu.br

A. Klassen - M. F. M. Tavares

Universidade de São Paulo, Instituto de Química,

Butantã, P.O. Box 26077, São Paulo 05513-970, Brazil

J. M. David

Universidade Federal da Bahia, Instituto de Química, Campus

Universitário de Ondina, Salvador 40170-290, Bahia, Brazil colour and flavour. Wine has been the subject of many analytical studies [1-3]. Actually these compounds have been reported to have multiple biological effects such as, anti-inflammatory action, inhibition of platelet aggregation, and antimicrobial activities [4]. A major part of the phenolics in wines may act as antioxidants [5]. Many works have been published dealing with the analysis of red wine polyphenols and the relationship between polyphenol content and antioxidant capacity. The antioxidant properties [6] of red wines have been correlated with their content of flavonols [7, 8], anthocyanins [9, 10], and tannic acid [11], although it is believed that the antioxidant properties of red wines are linked with the total polyphenol concentration $[12,13]$ rather than with specific compounds. Many methods have been used for analysis of phenolic compounds in wine, with high performance liquid chromatography as the method of choice [14-17]. The HPLC technique has high analysis time, which varies between 30 and $60 \mathrm{~min}$ [18].

On the other hand, capillary electrophoresis (CE) [19, 20] is an efficient technique, which spends small sample and electrolyte consumption and rapid analyses, with separation times of few minutes. This last characteristic is the main advantage versus chromatographic methods, which makes $\mathrm{CE}$, micellar electrokinetic chromatography (MEKC) [21], a diode array detector (DAD), electrochemical [22] and fluorimetric detection [23] of great utility in routine analysis, monitoring of processes in a number of industrial fields and in screening methods to give a fast binary response. In addition, CE is relatively well suited to analysis of samples with complex matrices, as it allows in-capillary concentration through electrokinetic stacking. Phenolic compounds have been determined in wine and must using CE [24, 25]. Very often this technique enables the determination of low concentration levels of one analyzed analyte in the presence 
of many other interfering and coeluting components which is possible in combination with an effective sample preparation technique. It is generally known that clean-up and preconcentration of analytes from the biological matrix are the most difficult and time-consuming steps. Traditional separation techniques, include a solvent extraction of the sample [26, 27]. Among the electrophoretic methods, capillary zone electrophoresis (CZE) and micellar electrokinetic chromatography (MEKC) have been the most used for the analysis of wines and grapes [28-30]. The use of capillary electrophoresis for the determination of flavonols (kaempferol-3-rutinoside, rutin, avicularin, quercitrin, isoquercitrin, isorhamnetin, kaempferol and quercetin) present in fruit juices and wines was explored [31]. Another work studied the effect of organic solvents in the separation of flavonoids in wine by micellar electrokinetic capillary chromatography [32]. Electrophoresis is a separation technique with high efficiency based on differential migration of ionic or ionizable compounds when subjected to an electric field [33]. Thus, the purpose of this work is the determination of polyphenols in wine of Brazil's region Vale do São Francisco by CZE.

\section{Instrumentation and Capillary Conditioning}

Method development and evaluation, as well as sample analyses, were conducted in a capillary electrophoretic system; CE was performed with a "Backman-Coulter" P/ACE MDQ system (Fullerton, CA, USA) equipped with a DAD set at $280 \mathrm{~nm}$ for quantification. The temperature was controlled and stabilized at $25{ }^{\circ} \mathrm{C}$ using fluorocarbonbased cooling fluid. Samples and standard solutions were injected hydrodynamically (50 mbar for $5 \mathrm{~s}$ ) and constant voltage of $25 \mathrm{kV}$ was employed. The capillary was a fusedsilica (Polymicro Technologies, Phoenix, AZ, USA) with dimensions of $50 \mathrm{~cm}$ total length, $40.0 \mathrm{~cm}$ effective length, 50 um i.d. On each day of analysis, the capillary was conditioning by flushing with $1 \mathrm{~mol} \mathrm{~L}^{-1} \mathrm{NaOH}$ for $5 \mathrm{~min}$, followed by purified water (MilliQ System, Millipore, Bedford, MA, USA) for $5 \mathrm{~min}$ and the electrolyte solution for $30 \mathrm{~min}$. In between runs, the capillary was flushed with the electrolyte solution (1 min). The electrolytes composed of $10 \% \mathrm{MeOH}, 20 \mathrm{mM}$ TBS (sodium tetraborate); this solution was prepared daily and filtered through a $0.45-\mu \mathrm{m}$ membrane. All standards and samples were injected in triplicate.

\section{Reagents and Solvents}

All reagents were of analytical grade and solvents of chromatographic grade, used without previous purification. Methanol was purchased from Tedia Company (Fairfield, $\mathrm{OH}$, USA), hydrochloric acid and sodium tetraborate (TBS) from Merck (Darmstadt, Germany). Water was purified by deionization (18 $\mathrm{m} \Omega$ ) (Milli-Q system, Millipore, Bedford, MA, USA). The standard gallic acid, quercetin, myricetin and caffeic acid were purchased from Aldrich (St. Louis, MO, USA); syringic acid and kaempferol were from Fluka (St. Louis, MO, USA). Stock standard solutions of each of the 6 phenolic compounds were prepared at $1,000 \mathrm{mg} \mathrm{L}^{-1}$ in $60: 40 \mathrm{v} / \mathrm{v}$ water/ethanol. Working solutions were prepared by mixing appropriate volumes of the stock solutions with $60: 40 \mathrm{v} / \mathrm{v}$ water/ethanol. The structure of the phenolic compounds is illustrated in Fig. 1.
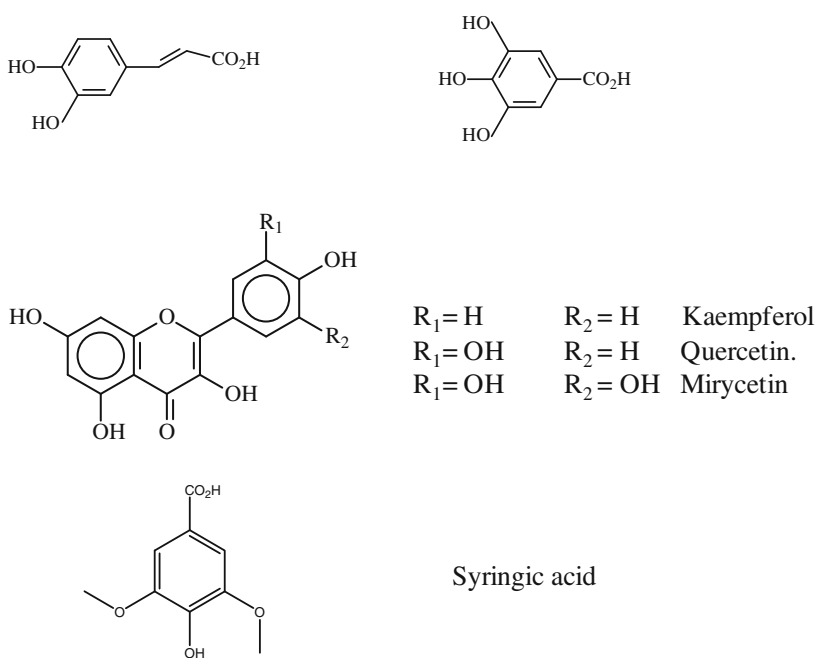

Fig. 1 Chemical structure of the phenolics

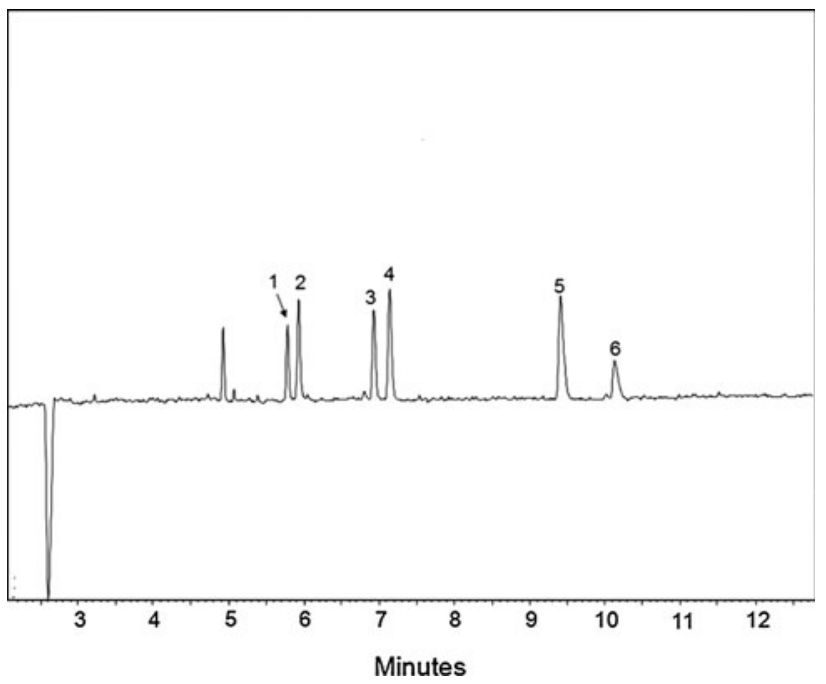

Fig. 2 Electropherograms of the phenolic compounds in mixture of standards. Buffer, TBS (sodium tetraborate) $20 \mathrm{mmol} \mathrm{L}^{-1}, 10 \%(\mathrm{v} / \mathrm{v})$; $\mathrm{pH}=9.0$; capillary silica capillary uncoated, $50.0 \mathrm{~cm} \times 50 \mu \mathrm{m}$ I.D.; applied potential, $+25 \mathrm{kV}$; detection, $\mathrm{UV}$ at $280 \mathrm{~nm}$ peak identification: 1 syringic acid, 2 kaempferol, 3 myricetin, 4 quercetin, 5 caffeic acid, 6 gallic acid 
Table 1 Analytical features of the CE method

\begin{tabular}{lllll}
\hline Analyte & $\begin{array}{l}\text { Detection limit } \\
\left(\mu \mathrm{g} \mathrm{mL}^{-1}\right)\end{array}$ & $\begin{array}{l}\text { Detection quantification } \\
\left(\mu \mathrm{gL}^{-1}\right)\end{array}$ & $\begin{array}{l}\text { Analytical } \\
\text { curves }\end{array}$ & $\begin{array}{l}\text { Coefficient of } \\
\text { correlation }\end{array}$ \\
\hline Syringic acid & 0.14 & 0.45 & $y=447.29 x-2214.9$ & 0.999 \\
Kaempferol & 0.19 & 0.58 & $y=684.7 x-1324.2$ & 0.999 \\
Myricetin & 0.25 & 0.84 & $y=398.01 x-1878.8$ & 0.999 \\
Quercetin & 0.31 & 1.03 & $y=945.13 x-1079.7$ & 0.999 \\
Caffeic acid & 0.33 & 0.96 & $y=1045.1 x-3116.4$ & 0.999 \\
Gallic acid & 0.22 & 0.72 & $y=1081.1 x-4881.3$ & 0.998 \\
\hline
\end{tabular}

\section{Samples}

Six samples of different types of red wine were purchased from a supermarket in Bahia, Brazil. These wines were chosen to get a good representation of wines produced in the region of Vale do São Francisco-Bahia. The samples of Brazilian wines are novelties in the work, because the region is uncommon for elaboration of wines. These wines are from a tropical region (Shiraz, Cabernet Sauvignon, Cabernet Sauvignon/Shiraz; Shiraz; Ruby Cabernet, Tanat). All wines were stored in the dark at $4{ }^{\circ} \mathrm{C}$ until analysis.

\section{Liquid-Liquid Extraction (LLE)}

The contents of two freshly opened bottles were mixed and $1 \mathrm{~mL}$ was extracted with ethyl ether at a solvent/wine proportion of 8:5 mL, followed by hydrolysis with $100 \mu \mathrm{L}$ of hydrochloric acid for $15 \mathrm{~min}$ with magnetic stirring. The organic phase was separated from the aqueous phase, dried under nitrogen and dissolved with $2.5 \mathrm{~mL}$ of ethanol:water $60: 40 \mathrm{v} / \mathrm{v}$. The samples were filtered through a $0.45 \mu \mathrm{m}$ membrane (Millex LCR PTFE) (Millipore, Sao Paulo, Brazil). The analytes were identified by comparison of the migration times with those of standards and with wine spiked with standards under identical conditions, along with the spectra of the migrated solutes obtained with the PDA detector.

\section{Results and Discussion}

The polyphenols were identified in the electropherogram by comparing both migration time and spectral data obtained from real samples and standards and also with spiked real samples at different concentration levels. Peak areas were used for the quantification of the analytes. The conditions of the separation were optimized and published by Renato et.al. The electropherogram in the best condition is presented in Fig. 2.

\section{Analytical Features}

The analytical curves were produced from results obtained by injecting standard solutions in the range $5-100 \mu \mathrm{g} \mathrm{mL}^{-1}$.
Table 2 Spike test for phenolic compounds concentrations $\left(\mu \mathrm{gL}^{-1}\right)$ in Brazilian wines (Cabernet Sauvignon) obtained by CE

\begin{tabular}{llll}
\hline & $\begin{array}{l}\text { Content added } \\
\left(\mu \mathrm{g} \mathrm{mL}^{-1}\right)\end{array}$ & $\begin{array}{l}\text { Content found } \\
\left(\mu \mathrm{gL}^{-1}\right)\end{array}$ & Rec. $(\%)$ \\
\hline Gallic acid & 0.0 & 22.45 & 98.0 \\
Caffeic acid & 5.0 & 27.35 & \\
Syringic acid & 0.0 & 8.04 & 94.0 \\
& 5.0 & 8.13 & 98.5 \\
Quercetin & 0.0 & 10.10 & \\
Kaempferol & 0.0 & 3.58 & 96 \\
Myricetin & 2.0 & 5.50 & 99.5 \\
& 0.0 & 2.91 & 101 \\
\hline
\end{tabular}

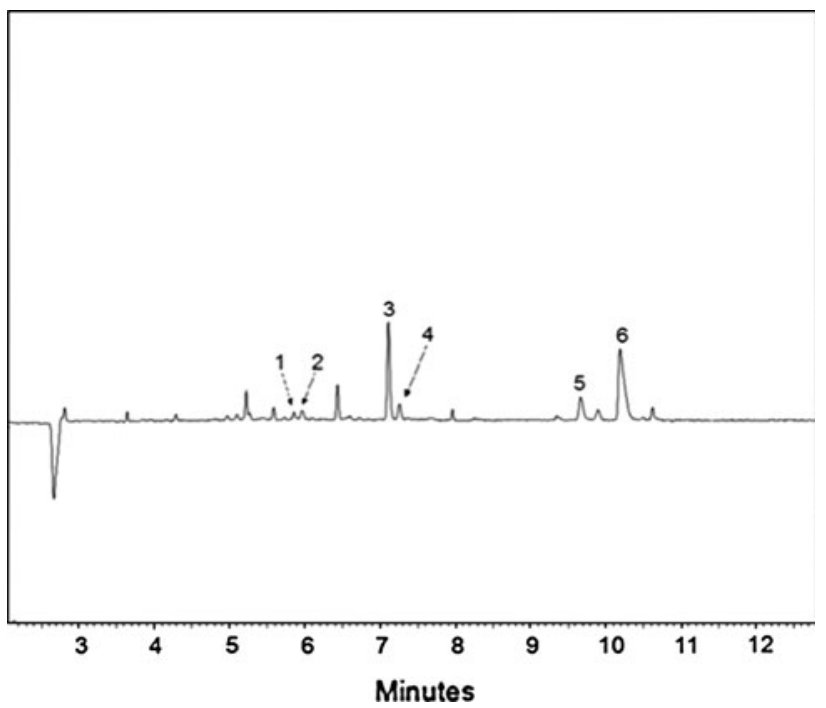

Fig. 3 Electropherograms of the phenolic compounds in red wine samples. Buffer, TBS (sodium tetraborate) $20 \mathrm{mmol} \mathrm{L}^{-1}, 10 \%(\mathrm{v} / \mathrm{v})$ $\mathrm{MeOH} ; \mathrm{pH}=9.0$; capillary silica capillary uncoated, $50.0 \mathrm{~cm} \times$ $50 \mu \mathrm{m}$ I.D.; applied potential, $+25 \mathrm{kV}$; detection, $\mathrm{UV}$ at $280 \mathrm{~nm}$ peak identification: 1 syringic acid, 2 kaempferol, 3 myricetin, 4 quercetin, 5 caffeic acid, 6 gallic acid 
Table 3 Phenolic compound concentrations $\left(\mu \mathrm{g} \mathrm{mL}^{-1}\right)$ in Brazilian wines obtained by the CE method

\begin{tabular}{|c|c|c|c|c|c|c|}
\hline Sample & Syringic & Kaempferol & Myricetin & Quercetin & Caffeic & Gallic \\
\hline Cabernet Sauvignon/Shiraz & $5.73 \pm 0.07$ & $4.33 \pm 0.21$ & $15.34 \pm 0.31$ & $1.68 \pm 0.05$ & $5.18 \pm 0.30$ & $15.77 \pm 0.58$ \\
\hline Cabernet Sauvignon & $8.13 \pm 1.90$ & $2.91 \pm 0.23$ & $25.13 \pm 4.82$ & $3.58 \pm 0.49$ & $8.04 \pm 0.25$ & $22.45 \pm 1.00$ \\
\hline Ruby Cabernet & $13.05 \pm 1.62$ & $3.03 \pm 0.13$ & $7.52 \pm 0.26$ & $2.97 \pm 0.29$ & $7.78 \pm 0.35$ & $22.35 \pm 1.07$ \\
\hline Tanat & $10.67 \pm 1.16$ & $3.11 \pm 0.21$ & $16.31 \pm 1.56$ & $4.03 \pm 0.67$ & $13.16 \pm 1.09$ & $15.47 \pm 1.54$ \\
\hline Cabernet Sauvignon & $10.43 \pm 0.13$ & $2.32 \pm 0.15$ & $23.95 \pm 0.43$ & $3.76 \pm 0.06$ & $7.83 \pm 0.07$ & $41.74 \pm 0.98$ \\
\hline Shiraz & $11.01 \pm 0.42$ & $2.48 \pm 0.05$ & $22.24 \pm 1.90$ & $3.79 \pm 0.31$ & $8.49 \pm 0.19$ & $28.09 \pm 1.04$ \\
\hline
\end{tabular}

The limit of detection (LOD) and limit of quantification (LOQ) were established by analyzing the calibration curves [34].

The corresponding regression equation and other characteristic parameters for the determination of the phenolic compounds are shown in Table 1 . The analytical curves exhibit excellent linear behaviour over the concentration range of about three orders of magnitude with the detection limits ranging from 1.59 to $2.24 \mu \mathrm{g} \mathrm{mL}^{-1}$ for all the analytes. The relative standard deviations (RSD) calculated for 20 and $32.5 \mu \mathrm{g} \mathrm{mL}^{-1}$ were 1.05 and $0.74 \%$ for gallic acid, 3.30 and $10.60 \mu \mathrm{g} \mathrm{mL}^{-1}$ were 3.08 and $1.37 \%$ for quercetin, 15.50 and $32.50 \mu \mathrm{g} \mathrm{mL}^{-1}$ were 1.05 and $0.74 \%$ for caffeic acid, 7.50 e $15.30 \mu \mathrm{g} \mathrm{mL}^{-1}$ were 3.0 and $0.8 \%$ for myricetin, 2.30 e 14.20 were 1.01 and $3.50 \%$ for kaempferol, respectively. Absolute recoveries were evaluated to compare the concentrations found in wine sample spiked with known amounts of each polyphenol. The concentrations were obtained using the calibration curve, and the values obtained were about 98 and $101 \%$ of the recuperation (Table 2).

\section{Polyphenols of Brazilian Wines}

Figure 3 presents the electropherogram of the phenolic compounds in the red wine samples and Table 3 shows the concentrations of the six phenolic compounds determined in six Brazilian wines: Gallic $\left(16-42 \mu \mathrm{g} \mathrm{mL}^{-1}\right)$, caffeic (3.16-5.18 $\left.\mathrm{g} \mathrm{mL}^{-1}\right)$, syringic $\quad\left(5.73-13.05 \mu \mathrm{g} \mathrm{mL}^{-1}\right)$, kaempferol $\left(2.32-4.33 \mu \mathrm{g} \mathrm{mL}^{-1}\right)$, quercetin (1.68-4.03 $\left.\mu \mathrm{g} \mathrm{mL}^{-1}\right)$, myricetin $\left(7.52-25.13 \mu \mathrm{g} \mathrm{mL}^{-1}\right)$. In the literature data on phenolic compounds and the ranges are reported: $39-61 \mu \mathrm{g} \mathrm{mL}^{-1}$ gallic acid, $2.2-8.7 \mu \mathrm{g} \mathrm{mL}^{-1}$ caffeic acid [14], syringic (3.62-7.46 $\mu \mathrm{g} \mathrm{mL}^{-1}$ ) [35], kaempferol (0.17-0.54), quercetin (3.19-16.70), myricetin (1.91-11.87 $\mathrm{g} \mathrm{mL}^{-1}$ ) for red wines. In these wines gallic acid is the major component followed by myricetin. The concentration ranges of the phenolic compounds found in the Brazilian wines is comparable with the data obtained in the literature, even though showing small differences. In an another work the reported values of the concentrations for the phenolic compounds found in red wine, determined by
GC using matrix solid-phase dispersion extraction, were: (105-33.78 $\left.\mathrm{g} \mathrm{mL}^{-1}\right)$, caffeic acid $\left(0.24-4.10 \mu \mathrm{g} \mathrm{mL}^{-1}\right)$, syringic acid (1.21-5.34 $\left.\mu \mathrm{g} \mathrm{mL}^{-1}\right)$, kaempferol (0.05-3.04 $\mu \mathrm{g} \mathrm{mL}^{-1}$ ) [36]. The wide variation in the phenolic concentrations obtained in this work can be explained, at least in part, by analytical and natural variability of the data on the levels of these compounds, since phenolic composition presented in the red wine is more complex and the chemical composition of the wine is intimately correlated with the origin of the grapes, soil type, climate and the process of production and conservation during preparation of the wine. The grapes cultivated in the São Francisco region, are new and are still being developed by adaptation processes to the soil and the climate. The wines produced in this region are young; however, they are of good quality.

\section{Conclusion}

A simple, versatile and low-cost CE method, which utilizes methanol, sodium tetraborate and silica capillaries, was applied for rapid and simultaneous determination of polyphenolic compounds in Brazilian wines. The method provided good limits of detection and quantification, as well as linearity, peak area repeatability and good recovery in the concentration levels studied. Applied to the Brazilian wines, good precision was confirmed.

Acknowledgments The authors are grateful to PRONEX/FAPESB, FAPESP, Conselho Nacional de Desenvolvimento Científico e Tecnológico $(\mathrm{CNPq})$ and CAPES for providing grants and fellowships.

\section{References}

1. Álvarez MI, Moreno M, Jos Á, Cameán AM, González AG (2007) Microchem J 87:72-76

2. Moreno IM, González-Weller D, Gutierrez V, Marino M, Cameán AM, González GA, Hardisson A (2008) Microchem J 88:56-60

3. Santalad A, Burakham R, Srijaranai S, Grudpan K (2007) Microchem J 86:209-215

4. Goldberg DM, Karumanchiri A, Soleas GJ, Tsang E (1999) Am J Enol Vitic 50:185-189 
5. Maxwell S, Cruickshank A, Thorpe G (1994) Lancet 344:193-194

6. Kelebek H, Selli S, Canbas A, Cabaroglu T (2009) Microchem J 91:187-192

7. Teissedre PL, Frankel EN, Waterhouse AL, Peleg H, German JB (1996) J Sci Food Agric 70:55-61

8. Simonetti P, Pietta P, Testolin G (1997) J Agric Food Chem 45:1152-1155

9. Ghiselli A, Nardini M, Baldi A, Scaccini C (1998) J Agric Food Chem 46:361-367

10. Pellegrini N, Simonetti P, Gardana C, Brenna O, Brighenti F, Pietta P (2000) J Agric Food Chem 48:732-735

11. Larrauri JA, Sanchez-Moreno C, Ruperez P, Saura-Calixto F (1999) J Agric Food Chem 47:1603-1606

12. Frankel EN, Waterhouse AL, Teissedre PL (1995) J Agric Food Chem 43:890-894

13. Esparza I, Santamaría C, Calvo MI, Fernández JM (2009) Microchem J 91:32-39

14. Castellari M, Sartini E, Fagiani A, Arfelli G, Armati A (2002) J Chromatogr A 973:221-227

15. Arnous A, Makris D, Kefalas P (2001) J Agric Food Chem 49:5736-5742

16. Brenna O, Pagliarini E (2001) J Agric Food Chem 49:4841-4844

17. de Dias FS, Lovillo MP, Barroso CG, David JM (2010) Microchem J 96:17-20

18. Revilla E, Ryan JM (2000) J Chromatogr A 881:461-469

19. Peng YY, Liu FH, Ye JN (2004) Chromatographia 60:597-602

20. Vanhoenacker G, Villiers A, de Lazou K, de Keukeleire D, Sandra P (2001) Chromatographia 54:309-315
21. Watanabe AT, Yamamoto A, Nagai S, Terabe S (1998) J Chromatogr A 793:409-413

22. Gao L, Chu Q, Ye J (2002) Food Chem 78:255-260

23. Rodriguez-Delgado MA, Malovaná S, Pérez JP, Borges T, Garcia Montelongo FJ (2001) Chromatogr A 912:249-257

24. Sáenz-López R, Fernández-Zurbano P, Tena MT (2004) J Chromatogr A 1052:191-197

25. Vendar P, Papouskova B, Müller L, Bartak P, Stavek J, Pavlousek P, Lemr K (2005) J Sep Sci 28:1291-1300

26. Diaz GT, Meras ID, Rodriguez DA (2007) Anal Bioanal Chem 387:1999-2007

27. Bru ER, Barroso CG, Cela R, Bustamante JAP (1996) Analyst 121:297-302

28. Berli F, D'Angelo J, Cavagnaro B, Bottini R, Wuilloud R, Silva MFJ (2008) Agric Food Chem 56:2892

29. Rodriguez-Delgado MA, Perez ML, Corbella R, Gonzalez G, Montelongo FJ, Garcia J (2000) Chromatogr A 871:427-438

30. Huang H-Y, Lien W-C, Chiu C-W (2005) J Sep Sci 28:973-981

31. de Fernández Simón B, Estrella I, Hernández T (1995) Chromatographia 41:389-392

32. Rodríguez-Delgado MA, Pérez JP, Sánchez MJ, García Montelongo FJ (2000) Chromatographia 52:289-294

33. Bier M (ed) (1959) Electrophoresis, theory, methods and applications. Academic Press Inc., New York p 225

34. Numanoğlu E, Hakki Boyaci İ, Topcu A (2008) J Food Drug Anal 16:74-80

35. La Torre GL, Saitta M, Vilasi F, Pellicanó T, Dugo G (2006) Food Chem 94:640-650

36. Minuti L, Pellegrino R (2008) J Chromatogr A 1185:23-30 